\title{
Viral Meningitis
}

National Cancer Institute

\section{Source}

National Cancer Institute. Viral Meningitis. NCI Thesaurus. Code C118298.

Inflammation of the membranes surrounding the brain and spinal cord due to a viral infection. 